\title{
An Optimal Decision Assessment Model Based on the Acceptable Maximum LGD of Commercial Banks and Its Application
}

\author{
Baofeng Shi, ${ }^{1}$ Bin Meng, ${ }^{2}$ and Jing Wang ${ }^{1}$ \\ ${ }^{1}$ College of Economics \& Management, Northwest A\&F University, Yangling, Shaanxi 712100, China \\ ${ }^{2}$ Collaborative Innovation Center for Transport Studies, Dalian Maritime University, Dalian 116026, China \\ Correspondence should be addressed to Bin Meng; mengbinfly@163.com
}

Received 18 June 2016; Revised 8 August 2016; Accepted 15 August 2016

Academic Editor: Guo Chen

Copyright (c) 2016 Baofeng Shi et al. This is an open access article distributed under the Creative Commons Attribution License, which permits unrestricted use, distribution, and reproduction in any medium, provided the original work is properly cited.

\begin{abstract}
This paper introduces a novel decision assessment method which is suitable for customers' credit risk evaluation and credit decision. First of all, the paper creates an optimal credit rating model, and it consisted of an objective function and two constraint conditions. The first constraint condition of the strictly increasing LGDs eliminates the unreasonable phenomenon that the higher the credit rating is, the higher the LGD (loss given default) is. Secondly, on the basis of the credit rating results, a credit decision-making assessment model based on measuring the acceptable maximum LGD of commercial banks is established. Thirdly, empirical results using the data on 2817 farmers' microfinance of a Chinese commercial bank suggest that the proposed approach can accurately find out the good customers from all the loan applications. Moreover, our approach contributes to providing a reference for decision assessment of customers in other commercial banks in the world.
\end{abstract}

\section{Introduction}

There are a lot of decision assessment issues in reality, such as production scheduling assessment, transportation routing assessment, economy development evaluation, and risk assessment. In order to cope with these problems, lots of decision-making optimization and evaluation approaches have been created in the existing studies [1-4]. However, only a small part of them have been widely used in the real world. Much more attention should be paid to the application of the decision-making optimization and evaluation models. For example, in credit risk evaluation of commercial banks, an accurate optimal decision-making evaluation model is in urgent need of selecting the good customers from all the loan applications, which can help the bankers, the society, and the bond investors to reduce loss [5].

The main proposed references to the evaluation of credit risk of commercial banks can be divided into two categories. The first category concentrates on the establishment of credit scoring models, and the second category focuses on the division of credit ratings or the ascertaining method of credit threshold. Early studies included the establishment of a fivevariable $Z$-Score credit risk evaluation model, and the Zeta rating model can optimize the $Z$-Score model by using statistics discrimination techniques [6, 7]. Min and Lee proposed a credit scoring model based on data envelopment analysis (DEA) methods [8]. Using the data information of the New York Stock Exchange, Hwang et al. established an ordered semi-parametric Probit credit rating model by substituting ordered semi-parametric function for the linear regression function [9]. Gupton et al. utilized transition matrices to describe debtor's probability of credit rating change, thereby creating an optimal CreditMetrics credit rating model [10]. Recent methods have advanced Bayesian Analysis Techniques to help deal with the issue of loss from bad loans [11]. Expert information systems and artificial intelligence techniques are other important approaches for credit risk assessment of commercial banks. For example, predicted accuracy techniques, like multiple classifiers and classifier ensembles, were a major testing methodology with expert information systems and artificial intelligence techniques [12-14].

Research on how to issue loans requires the division of credit ratings and the ascertaining method of credit threshold. For the past few years, more and more scholars and bankers began to monitor and divide the customers' credit ratings, which deepens the associated theoretical research 
and practical processes of credit risk management. Gorzałczany and Rudziński classified customers' credit levels into 10 different grades by using a multiobjective genetic optimization approach [15]. By creating the objective function maximizing the deviation matrix $\mathbf{A}$ between default customers and nondefault customers and minimizing the deviation matrix $\mathbf{B}$ among indices in the same group (default customer group or nondefault customer group), the optimal weights had been obtained. Then, Shi et al. proposed a credit risk assessment model, which was suitable for the credit rating classification of imbalanced data [5]. According to the distribution of the number of customers, some researchers divided the loan customers into 9 credit ratings, namely, AAA, AA, A, BBB, BB, B, CCC, CC, and C [16, 17]. FlorezLopez estimated customers' $\mathrm{PD}$ (probability of default) through MDA (multiple discriminant analysis), Logit, and decision tree methods and then classified customers into 5 credit grades by setting a variable for each grade $(\mathrm{AA}=$ $1, \ldots, \mathrm{B}=5$ ) [18]. After getting the numerical solution for loan pricing through mathematical analysis, Pascucci et al. (2013) calculated the credit threshold and then created a customer loan pricing model [19]. Chen and Cheng graded the credit level by combining a rough set classifier with the minimum entropy principle approach. Then, they determined the credit ratings for issuing loans from their subjective experience [20]. Guo et al. established an evaluation model of customers' credit risk by linking the personal loan on P2P lending platform with portfolio optimization [21]. Jones et al. predicted the variation tendency of customer's credit level through binary classifier and then ascertained the credit threshold [22].

The above studies have made great progress in handling decision evaluation issues of credit risk of commercial banks. However, further studies on the following problems are still needed. First of all, the existing credit risk assessment results have the unreasonable phenomenon that the higher credit rating customers also have the higher loss given default (i.e., LGD). It will generate a result that a bank can issue loans to the customers who are under the break-even point of the bank, which can increase the bank's loan loss. Secondly, the existing credit rating classification results do not establish the connection between the credit rating classification results and the break-even point of commercial banks, so the classification methods do not have the functions of credit decisions. Bankers or credit clerks cannot locate the qualified customers who can realize the bank's target profit.

To fill in the above gaps, this study advances in three aspects. First, this paper establishes a nonlinear credit risk assessment model which consisted of an objective function and two constraint conditions. The first constraint condition of the strictly increasing LGDs avoids the unreasonable phenomenon, like higher ratings with higher LGDs. Second, by measuring the break-even point threshold of commercial banks, this paper works out the maximum annual LGD which the bank can bear and then introduces the break-even point into the credit rating results. Thus, the relation between the target profit of bank and the credit threshold can be known, which makes up for the deficiency of previous researches. Third, an empirical study on the decision-making data of 2817 farmers' microfinance of a large-scale Chinese commercial bank in 28 provinces is carried out in order to verify the accuracy of the proposed model.

The rest of the paper is organized as follows. Section 2 introduces the methodology of the paper. Section 3 presents the data and empirical analysis of our decision assessment model for 2817 farmers' microfinance in China. Section 4 is the conclusions.

\section{Design and Methodology of the Study}

In this section, we introduce an optimal credit decision assessment model based on the acceptable maximum LGD of commercial banks. According to the relation between the annual owed loan capital and interest and annual receivable loan capital and interest of customers' loan, together with the credit scores of customers, the customers are classified into 9 credit ratings in this paper based on the principle that the customer with a higher credit rating is lower in annual LGD. A step-by-step instruction is provided.

Step 1. Sequence the customers in a descending order according to their credit scores, and calculate the customer's LGD.

Step 2. Divide the customers' credit ratings in terms of the principle that the higher the credit rating is, the lower the LGD is.

Step 3. Calculate the break-even point threshold.

Step 4. Make credit decisions.

2.1. Calculation of the Customer's LGD. According to the Basel Capital Accord III [23], it will be deemed to be a defaulter if the client fails to repay the loan in full or on time. Then, the loan customers who fail to pay off the principal and interest within 90 days after the maturity date $T$ of loan should be regarded as delinquent customers in this paper. The annual LGD of customers in a certain credit grade can be obtained from the ratio of the total annual owed loan capital and interest in this grade to its total annual receivable loan capital and interest. The total of annual owed loan capital and interest of customers refers to the total amount of annual loss (outstanding principal and interest) customers that have caused the bank 90 days after the maturity date $T$ of loan. The total of annual receivable loan capital and interest of customers refers to the total amount of loan (principal and interest) that customers should repay to the bank each year.

Let $\mathrm{LGD}_{j}$ denote the annual loss given default of the $j$ th credit rating $(j=1,2, \ldots, 9)$, let $L_{j}$ denote the total of the annual owed loan capital and interest of microfinance of all the customers in the $j$ th credit rating, let $R_{j}$ denote the total of the annual receivable loan capital and interest of microfinance of all the customers in the $j$ th credit rating, let $n$ denote the total number of customers, let $R_{i j}$ denote the annual receivable loan capital and interest of the microfinance 
of the $j$ th credit rating on the $i$ th customer, and let $L_{i j}$ denote the annual owed loan capital and interest of the microfinance of the $j$ th credit rating on the $i$ th customer. Then, the $\mathrm{LGD}_{j}$ can be expressed as

$$
\mathrm{LGD}_{j}=\frac{L_{j}}{R_{j}},
$$

where $R_{j}$ and $L_{j}$ can be computed by using (2) and (3), respectively:

$$
\begin{aligned}
& R_{j}=\sum_{i=1}^{n} R_{i j}, \\
& L_{j}=\sum_{i=1}^{n} L_{i j} .
\end{aligned}
$$

2.2. Establishment of an Optimal Credit Rating Model. In this section, we will create a nonlinear programming model to classify the customers' credit ratings. According to the credit rating requirements of the commercial bank and the China Banking Regulatory Commission (CBRC) [24, 25], we divide the loan customers into nine ratings.

(1) Establish an Objective Function. Let $\mathrm{LGD}_{j}$ denote the loss given default of the $j$ th credit rating, and $j=$ $1,2, \ldots, 9$, respectively, represents nine credit ratings, that is, AAA, AA, ..., C. Establish an objective function, that is, the minimum distance of all adjacent rating LGDs,

$$
\begin{aligned}
\text { Obj: } \min f= & \left(\mathrm{LGD}_{9}-\mathrm{LGD}_{8}\right)^{2}+\left(\mathrm{LGD}_{8}-\mathrm{LGD}_{7}\right)^{2} \\
& +\cdots+\left(\mathrm{LGD}_{2}-\mathrm{LGD}_{1}\right)^{2} .
\end{aligned}
$$

The specialty of (4) is that by creating the objective function minimizing the distance of LGDs of all adjacent credit ratings, it ensures that the LGD distribution of the selected credit rating result is the closest to an isosceles triangle.

(2) Constraint Condition 1. The LGDs increase strictly. Namely,

$$
0<\mathrm{LGD}_{1}<\mathrm{LGD}_{2}<\cdots<\mathrm{LGD}_{9} \leq 1
$$

As we all know, only national debt's LGD equals 0 , and LGD $=1$ shows that all of the credit rating customers are default customers; so the value of LGD which is more than 0 and less than or equal to 1 is logical in (5).

(3) Constraint Condition 2. It is the equality constraint to calculate $\mathrm{LGD}_{j}$ of the $j$ th credit rating. The $\mathrm{LGD}_{j}$ can be expressed as (1).

In a word, the optimal credit rating model can be written as (6). It should be pointed out that if researchers want to grade the loan customers into five ratings [25], they can substitute the number nine for the number five in (6). Then, the calculation results can be obtained through the $\mathrm{C}++$ software,

$$
\begin{aligned}
\min & f \\
& =\left(\mathrm{LGD}_{9}-\mathrm{LGD}_{8}\right)^{2}+\left(\mathrm{LGD}_{8}-\mathrm{LGD}_{7}\right)^{2}+\cdots
\end{aligned}
$$

$$
\begin{gathered}
+\left(\mathrm{LGD}_{2}-\mathrm{LGD}_{1}\right)^{2} \\
\text { s.t. } \quad 0<\mathrm{LGD}_{1}<\mathrm{LGD}_{2}<\cdots<\mathrm{LGD}_{9} \leq 1 \\
\mathrm{LGD}_{j}=\frac{\sum_{i=1}^{n} R_{i j}}{\sum_{i=1}^{n} L_{i j}}, \quad j=1,2, \ldots, 9 .
\end{gathered}
$$

2.3. Calculation of the Break-Even Point Threshold. In order to compute the break-even point threshold of customers' loan, we have to calculate the ratio of financial costs of customers' microfinance $r_{C}$, the minimum target rate of return of customers' microfinance $r_{P}$, the ratio of the annual owed loan capital and interest to the annual receivable loan capital, and interest $r_{D}$.

(1) The Ascertaining of the Ratio of Financial Costs $r_{C}$. Let $r_{C}$ denote the ratio of financial costs, $F_{1}$ be the expenses of interest on deposit, $F_{2}$ be the charge against revenue, and $P$ be the total loan, we have Financial Costs = (Interest Expenses on Deposit + Charge against Revenue)/Total Loan; that is,

$$
r_{C}=\frac{\left(F_{1}+F_{2}\right)}{P} .
$$

(a) Calculation of the Expenses of Interest on Deposit $F_{1}$. Not all the deposits in the bank can be used for loan. To ensure the deposit withdrawal of customer and the operation of capital, the bank has to deposit some money in the People's Bank of China as required reserves. Therefore, the deposit used for loan by the bank does not include the part deposited in the People's Bank of China. The People's Bank of China should pay the interest of required reserves to the bank so as to make up the loss of bank for not operating the capital. Therefore, expenses of interest on deposit $F_{1}$ is calculated by adding the deposit interests of loan principal and the deposit interests of the corresponding required reserves of loan principal required by the People's Bank of China and deducting the interest income of the corresponding required reserves of loan principal deposited in the People's Bank of China.

Let $F_{1}$ denote the expenses of interest on deposit, $P$ denote the total loan, $r_{1}$ denote the one-year deposit rate, $L_{\text {re }}$ denote the corresponding required reserves of total loan required by the People's Bank of China, and $r_{\text {re }}$ denote the deposit reserve rate. Then,

$$
F_{1}=P \times r_{1}+L_{\mathrm{re}} \times r_{1}-L_{\mathrm{re}} \times r_{\mathrm{re}} .
$$

Given $P=$ total loan, $L_{D}=$ the corresponding deposit of total loan, and $\varepsilon=$ rate of legal deposit reserve, we have

$$
P=L_{D} \times(1-\varepsilon) .
$$

Then, the corresponding deposit of total loan $L_{D}$ can be written as

$$
L_{D}=\frac{P}{(1-\varepsilon)} \text {. }
$$


The corresponding deposit of total loan $L_{D}$ times the rate of legal deposit reserve $\varepsilon$ is the corresponding required reserves of total loan required by the People's Bank of China $L_{\text {re: }}$ :

$$
L_{\mathrm{re}}=L_{D} \times \varepsilon
$$

Substituting (10) into (11), we have

$$
L_{\mathrm{re}}=\frac{P \times \varepsilon}{1-\varepsilon} .
$$

Equation (12) is the calculation formula of the corresponding required reserves of total loan required by the People's Bank of China $L_{\text {re }}$.

Substitute (11) into (8), and then

$$
\begin{aligned}
F_{1} & =P \times r_{1}+L_{\mathrm{re}} \times r_{1}-L_{\mathrm{re}} \times r_{\mathrm{re}} \\
& =P \times r_{1}+\frac{P \times \varepsilon}{1-\varepsilon} \times r_{1}-\frac{P \times \varepsilon}{1-\varepsilon} \times r_{\mathrm{re}} .
\end{aligned}
$$

(b) Calculation of the Charge against Revenue $F_{2}$. Charge against revenue refers to all the expenses the bank has to pay in business operation and management except the expenses of interest on deposit. It is made up of operating expenses, depreciation charges of fixed assets, and other business expenses.

Let $F_{2}$ be the charge against revenue, $E_{1}$ be the operating expenses, $E_{2}$ be the depreciation charges of fixed assets, and $E_{3}$ be other business expenses, and then

$$
F_{2}=E_{1}+E_{2}+E_{3} \text {. }
$$

(2) The Ascertaining of the Minimum Target Rate of Return $r_{P}$. Let $C$ denote the core capital of bank, let $C_{d}$ denote the deduction of core capital, let $\alpha_{i}$ denote the risk weight of risk asset $i$, let $A_{i}$ denote the line of risk asset $i$, let $M_{c}$ denote the market risk capital, and let $\beta_{\text {min }}$ denote the minimum core capital adequacy ratio stipulated by CBRC [26]. We have

$$
\frac{C-C_{d}}{\sum \alpha_{i} A_{i}+12.5 M_{c}} \geq \beta_{\min }
$$

where $\sum \alpha_{i} A_{i}$ is the sum of different risk-weighted assets and $\left(\sum \alpha_{i} A_{i}+12.5 M_{c}\right)$ is the sum of risk-weighted assets and 12.5 times market risk capital.

Let ROE be the rate of return on common stockholders' equity, $\mathrm{GP}^{\prime}$ be the total of the target net profit of bank, and $C^{\prime}$ be the net asset of bank, and then

$$
C^{\prime}=\frac{\mathrm{GP}^{\prime}}{\mathrm{ROE}} .
$$

The net asset $C^{\prime}$ includes capital stock, capital reserve, surplus reserve, statutory public welfare fund, and undistributed profit. The core capital $C$ includes capital stock, capital reserve, surplus reserve, and undistributed profit. Let us suppose that the net asset of bank $C^{\prime}$ equals to the core capital of bank C. After substituting (16) into (15), we have

$$
\begin{aligned}
\mathrm{GP}^{\prime} & \geq \mathrm{ROE} \times\left[\left(\alpha_{i} A_{i}+12.5 M_{c}\right) \times \beta_{\min }+C_{d}\right]=\mathrm{ROE} \\
\times & {\left[\left(\alpha_{i} A_{i}+12.5 \times \sum A_{i} \times \frac{M_{c}}{\sum A_{i}}\right) \times \beta_{\min }+\sum A_{i}\right.} \\
& \left.\times \frac{C_{d}}{\sum A_{i}}\right],
\end{aligned}
$$

where $M_{c} / \sum A_{i}$ refers to the market risk capital of the average asset of bank and $C_{d} / \sum A_{i}$ refers to the deduction of core capital of the average asset of bank. When the bank issues a loan, the sum of different risk-weighted assets $\sum \alpha_{i} A_{i}$ can be replaced by the risk asset $\alpha P$, and the total assets of bank $\sum A_{i}$ can be replaced by the total loan $P$. Then, there is

$$
\begin{aligned}
\mathrm{GP}^{\prime} & \geq \mathrm{ROE} \\
\times & {\left[\left(\alpha P+12.5 \times P \times \frac{M_{c}}{\sum A_{i}}\right) \times \beta_{\min }+P \times \frac{C_{d}}{\sum A_{i}}\right] . }
\end{aligned}
$$

Divide the maximum net profit $\mathrm{GP}^{\prime}$ of a loan by the total loan $P$, and we get the target rate of return $r_{P}$,

$$
\begin{aligned}
r_{P} & =\frac{\operatorname{ROE} \times\left[\left(\alpha P+12.5 \times P \times\left(M_{c} / \sum A_{i}\right)\right) \times \beta_{\min }+P \times\left(C_{d} / \sum A_{i}\right)\right]}{P}=\mathrm{ROE} \\
& \times\left[\left(\alpha+12.5 \times \frac{M_{c}}{\sum A_{i}}\right) \times \beta_{\min }+\frac{C_{d}}{\sum A_{i}}\right],
\end{aligned}
$$

from which the minimum target rate of return $r_{P}$ can be obtained. Equation (19) is to get the minimum legal target rate of return $r_{P}$ of bank according to the stipulations of Basel New Capital Accord III and CBRC on minimum core capital adequacy ratio.

(3) The Ascertaining of the Ratio $r_{D}$. Generally, the loan rate $r$ based on cost plus is obtained by adding the financial costs, target rate of return, and loss given default irrespective of business tax [27]. Let $r$ denote the lending rate, let $r_{D}$ denote the loss given default, and then

$$
r=r_{C}+r_{P}+r_{D}
$$

We have

$$
r_{D}=r-r_{C}-r_{P} .
$$


TABLE 1: Original data of farmers for credit decision assessment.

\begin{tabular}{lcccc}
\hline (1) Index & (2) Farmer number & (3) Credit scores & $\begin{array}{c}\text { (4) Receivable loan capital } \\
\text { and interest } R_{i j}(\text { Yuan })\end{array}$ & $\begin{array}{c}\text { (5) Owed loan capital and } \\
\text { interest } L_{i j}(\text { Yuan })\end{array}$ \\
\hline 1 & Farmer 2154 & 100 & 3259642 & 0 \\
2 & Farmer 2155 & 100 & 2173095 & 0 \\
3 & Farmer 2825 & 99.24 & 20074635 & 0 \\
4 & Farmer 2943 & 99.13 & 10605947 & 0 \\
$\vdots$ & $\vdots$ & $\vdots$ & $\vdots$ & $\vdots$ \\
416 & Farmer 218 & 77.16 & 4470876 & 535791 \\
417 & Farmer 96 & 76.82 & 3551334 & 0 \\
$\vdots$ & $\vdots$ & $\vdots$ & $\vdots$ & $\vdots$ \\
2814 & Farmer 1109 & 1.69 & 8538718 & 8071240 \\
2815 & Farmer 1102 & 0.00 & 236826 & 236826 \\
2816 & Farmer 1103 & 0.00 & 255343.3 & 25343.3 \\
\hline
\end{tabular}

The loss given default $r_{D}$ refers to the ratio of the annual owed loan capital and interest to the annual receivable loan capital and interest, which shows the risk compensation of customer's default.

2.4. Making Credit Decisions Based on the Acceptable Maximum LGD of Commercial Banks. Through the financial costs of a bank and the minimum target rate of return deduced from the minimum core capital adequacy ratio stipulated by CBRC, this paper works out the maximum annual LGD which the bank can bear. Then, the threshold of customers' default can be obtained by comparing the calculated annual LGD of the customers in different credit ratings with the acceptable maximum annual LGD of bank. Loans will not be issued to those customers whose credit rating is lower than the break-even point threshold. Customers with a credit rating lower than the threshold are unable to get a loan from the bank.

\section{Empirical Study of the Proposed Model Based on Chinese Farmer Sample}

3.1. Sample and Data Source. In consideration of research purpose of decision assessment, we implement empirical study based on the 2817 farmers' microfinance data collected and screened from a Chinese state-owned commercial bank. Our project started with a talk between a chair manager of a Chinese state-owned commercial bank and one coauthor's supervisor about credit decision evaluation of farmers' microfinance loan when we attended the referee conference of major research project organized by National Science Foundation of China in September, 2009. After that, several meetings and communications of various forms have been made, and they lead to the formal start of this project. As a major participant, one coauthor is in charge of evaluation of farmer credit in the entire project. In order to guarantee the correctness and genuineness, all the sample data have been recertified in the bank's credit information system. The 2817 farmer samples include 28 provincial administrative provinces except Beijing Municipality, Yunnan Province, Tibet Autonomous Region, Taiwan Province, Hong Kong Autonomous Region, and Macao Autonomous Region in China, which guarantee data diversity, authenticity, and applicability [24]. It should be pointed out that the sample adopted in this paper is based on the evaluation index system and credit scoring model of farmer's microfinance. The indicators are selected by utilizing multicollinearity analysis. The credit scoring model is built by using logistic regression. Besides, the credit scores have been normalized. As the focus of this paper lies in the rating of credit and the lending decision, the detailed processes of index selecting and credit score calculation are not given (see details in [24]). The original data of farmers for credit decision assessment is shown in Table 1 [24].

\subsection{Application of the Decision Assessment Model}

(1) Divide the Farmers' Credit Ratings. Substitute the owed loan capital and interest $R_{i j}$ in the fourth column of Table 1 and the receivable loan capital and interest $L_{i j}$ in the fifth column of Table 1 into (1) to (6), and then the credit rating result can be obtained, as shown in Table 2 . The second column of Table 2 is the sample size of each credit rating. The third column is the ratio of the sample size of each credit rating to the total sample size. The fourth column is the score intervals of different credit ratings. The fifth column is the interval length of credit scores. The sixth column is the annual LGD of different credit ratings.

Figure 1 shows the distribution of the sample size of different credit ratings. Figure 2 is the pie chart of the sample size of different credit ratings. Figure 3 is the distribution of the annual loss given default of each credit rating. It is shown in Figures 1 and 2 that the majority of farmers are in Grade 
TABLE 2: Results of farmer's credit rating.

\begin{tabular}{|c|c|c|c|c|c|}
\hline (1) Credit rating & (2) Sample size & $\begin{array}{l}\text { (3) The ratio of the sample } \\
\text { size to the total sample size }\end{array}$ & $\begin{array}{l}\text { (4) Intervals of credit } \\
\text { scores }\end{array}$ & $\begin{array}{l}\text { (5) Interval length of } \\
\text { credit scores }\end{array}$ & (6) Annual LGD ${ }_{j}$ \\
\hline AAA & 416 & $14.77 \%$ & $77.16 \leq S<100$ & 22.84 & $0.114 \%$ \\
\hline $\mathrm{AA}$ & 1821 & $64.64 \%$ & $43.95 \leq S<77.16$ & 33.21 & $0.959 \%$ \\
\hline A & 145 & $5.15 \%$ & $43.39 \leq S<43.95$ & 0.56 & $1.598 \%$ \\
\hline BBB & 201 & $7.14 \%$ & $39.21 \leq S<43.39$ & 4.18 & $2.875 \%$ \\
\hline $\mathrm{BB}$ & 90 & $3.19 \%$ & $33.03 \leq S<39.21$ & 6.18 & $4.276 \%$ \\
\hline B & 34 & $1.21 \%$ & $31.46 \leq S<33.03$ & 1.57 & $4.919 \%$ \\
\hline CCC & 83 & $2.95 \%$ & $24.26 \leq S<31.46$ & 7.2 & $6.641 \%$ \\
\hline $\mathrm{CC}$ & 14 & $0.50 \%$ & $9.36 \leq S<21.46$ & 14.9 & $10.981 \%$ \\
\hline $\mathrm{C}$ & 13 & $0.46 \%$ & $0 \leq S<9.36$ & 9.36 & $14.797 \%$ \\
\hline
\end{tabular}

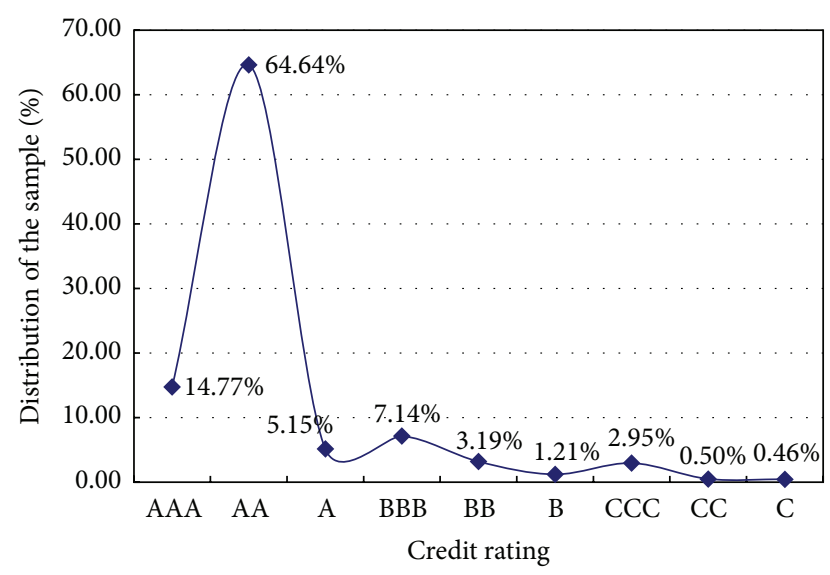

FIGURE 1: The distribution of the sample size of different credit ratings.

AA, which accounts for $64.64 \%$, and only $0.50 \%$ and $0.46 \%$ farmers are in CC and C, respectively. The grades of farmers that the bank has issued a loan for are high in credit ratings. Therefore, the risk of the bank will be low. As is shown in Figure 3 , the slopes of the distribution of the annual LGD of different credit ratings are basically the same. That is to say, the change in the slope between the annual LGD of each credit rating is small, which accords with the practical situation. So, the results of credit rating are reasonable.

(2) Calculate the Break-Even Point of Farmers' Microfinance. The related data for calculating the break-even point of farmers' microfinance comes from the Chinese state-owned commercial bank headquarters [24], as shown in Table 3. The descriptions of data are as follows. The loan rate $r$ in Row 1 is $10.5285 \%$, which is the highest lending rate of the Chinese commercial bank in history. The one-year deposit rate $r_{1}$ in Row 2 is from the interest table of 2014 benchmark deposit rate of RMB of financing institutions. The rate of legal deposit reserve $\varepsilon$ in Row 3 and the deposit reserve rate $r_{\text {re }}$ in Row 4 are from the People's Bank of China. The parameters in Row 5 to Row 9 are from the 2014 annual report of the Chinese

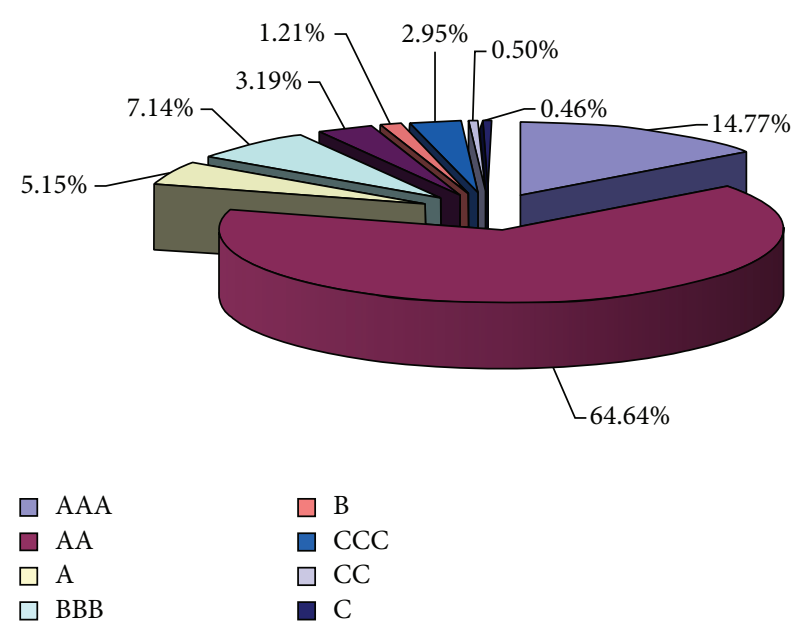

$\mathrm{BB}$

FIGURE 2: Pie chart of the sample size of different credit ratings.

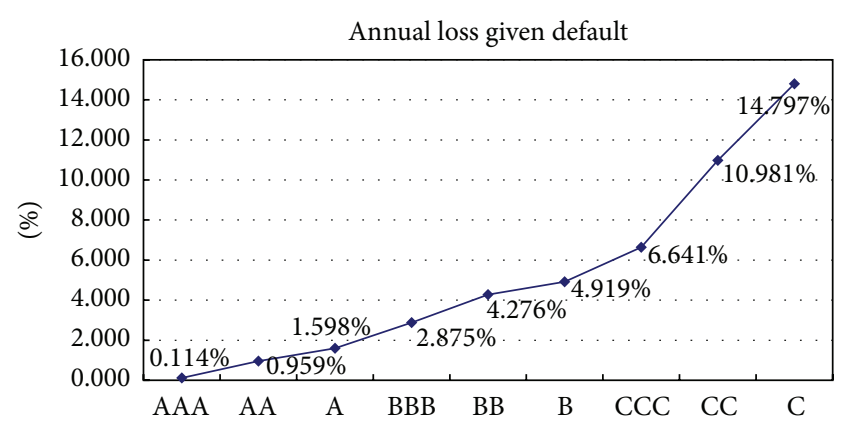

FIgURE 3: The distribution of the annual LGD of each credit rating.

commercial bank. The market risk capital $M_{c}$ equals 0 in Row 10 (according to [26], the commercial bank, whose total cash in the trading account is $10 \%$ higher or 8.5 billion more than its total assets, can calculate their market risk capital; the market risk capital $M_{c}$ equals 0 ). The core capital adequacy ratio $\beta$ equals $6 \%$ in Row 11 [26]. The parameters in Rows 
TABLE 3: The ascertaining of the acceptable maximum annual LGD.

\begin{tabular}{|c|c|c|c|c|}
\hline \multirow[b]{2}{*}{ (1) Index } & \multicolumn{3}{|c|}{ Indicators for calculating credit threshold } & \multirow[b]{2}{*}{ (5) Indicator data } \\
\hline & (2) Indicator & $\begin{array}{l}\text { (3) Intermediate } \\
\text { variable } 1\end{array}$ & $\begin{array}{l}\text { (4) Intermediate } \\
\text { variable } 2\end{array}$ & \\
\hline 1 & Loan rate & - & - & $10.5285 \%$ \\
\hline 2 & \multirow{6}{*}{$\begin{array}{l}\text { Financial costs } \\
\quad r_{C}=5.57 \%\end{array}$} & $\begin{array}{c}\text { Expenses of interest on } \\
\text { deposit } F_{1}(3318498 \\
\text { thousand Yuan) }\end{array}$ & $\begin{array}{c}\text { One-year deposit rate } \\
r_{1} \\
\text { Rate of legal deposit } \\
\text { reserve } \varepsilon\end{array}$ & $3.00 \%$ \\
\hline 4 & & \multirow{4}{*}{$\begin{array}{c}\text { Charge against revenue } \\
F_{2} \text { (2334148 thousand } \\
\text { Yuan) }\end{array}$} & Deposit reserve rate $r_{\text {re }}$ & $1.62 \%$ \\
\hline 5 & & & Operating expenses $E_{1}$ & $\begin{array}{c}2161448 \text { (thousand } \\
\text { Yuan) }\end{array}$ \\
\hline 6 & & & $\begin{array}{l}\text { Depreciation charges of } \\
\quad \text { fixed assets } E_{2}\end{array}$ & $\begin{array}{c}166427 \text { (thousand } \\
\text { Yuan) }\end{array}$ \\
\hline 7 & & & $\begin{array}{l}\text { Other business } \\
\text { expenses } E_{3}\end{array}$ & 6273 (thousand Yuan) \\
\hline 8 & & \multicolumn{2}{|c|}{ Total loan $P$} & $\begin{array}{c}101399562 \\
\text { (thousand Yuan) }\end{array}$ \\
\hline 9 & \multirow{6}{*}{$\begin{array}{l}\text { Target rate of } \\
\text { return } \\
r_{P}=0.71 \%\end{array}$} & \multicolumn{2}{|c|}{ Weighted average ROE } & $17.65 \%$ \\
\hline 10 & & \multicolumn{2}{|c|}{ Market risk capital $M_{c}$} & 0 (thousand Yuan) \\
\hline 11 & & \multicolumn{2}{|c|}{ Minimum core capital adequacy ratio $\beta$} & $6 \%$ \\
\hline 12 & & \multicolumn{2}{|c|}{ Deductions of core capital $C_{d}$} & $\begin{array}{c}85762 \text { (thousand } \\
\text { Yuan) }\end{array}$ \\
\hline 13 & & \multicolumn{2}{|c|}{ Assets $\sum A_{i}$} & $\begin{array}{c}256800388 \\
\text { (thousand Yuan) }\end{array}$ \\
\hline 14 & & \multicolumn{2}{|c|}{ Weight of the risk assets for loan $\alpha$} & 1 \\
\hline
\end{tabular}

12 and 13 are from the 2014 annual report of the Chinese commercial bank. The risk weight $\alpha$ equals 0 in Row 14 [26].

(a) Calculate the Ratio of Financial Costs $r_{C}$. Substitute the data of Rows 2, 3, and 4 in the fifth column of Table 3 into (13), and we get the expenses of interest on deposit $F_{1}$ :

$$
\begin{aligned}
F_{1}= & P r_{1}+\frac{P \varepsilon}{1-\varepsilon} \times r_{1}-\frac{P \varepsilon}{1-\varepsilon} \times r_{\text {re }} \\
= & 101399562 \times 3.00 \%+\frac{101399562 \times 16.5 \%}{1-16.5 \%} \\
& \times 3.00 \%-\frac{101399562 \times 16.5 \%}{1-16.5 \%} \times 1.62 \% \\
= & 3318498
\end{aligned}
$$

thousand Yuan, which is listed in the third column of Table 3.

Substitute the data in Rows 5, 6, and 7 in the fifth column of Table 3 into (14), and we get the charge against revenue $F_{2}=E_{1}+E_{2}+E_{3}=2161448+166427+6273=2334148$ thousand Yuan, which is listed in the third column of Table 3.

Substitute the expenses of interest on deposit $F_{1}=$ 3318498 thousand Yuan, the charge against revenue $F_{2}=$ 2334148 thousand Yuan, and the total loan $P=101399562$ thousand Yuan into (7), and we get the financial costs $r_{C}=$
$\left(F_{1}+F_{2}\right) / P=5.57 \%$, which is listed in the second column of Table 3.

(b) Calculate the Minimum Target Rate of Return $r_{P}$. Substitute the data in Rows 8-14 in the fifth column of Table 3 into (19), and we have

$$
\begin{aligned}
r_{P} & =\operatorname{ROE} \times\left[\left(\alpha+12.5 \frac{M_{c}}{\sum A_{i}}\right) \beta_{\min }+\frac{C_{d}}{\sum A_{i}}\right] \\
& =0.1765 \times\left[\left(1+12.5 \times \frac{0}{256800388}\right) \times 0.04\right. \\
& \left.+\frac{85762}{256800388}\right]=0.71 \%,
\end{aligned}
$$

which is listed in the second column of Table 3.

(c) Calculate the Acceptable Maximum Annual LGD (i.e., $r_{D}$ ). Substitute $r=10.5285 \%, r_{C}=5.57 \%$, and $r_{P}=0.71 \%$ into (21), and then $r_{D 1}=r-r_{C}-r_{P}=10.5285 \%-5.57 \%-$ $0.71 \%=4.25 \%$ can be obtained. That is to say, on the premise of guaranteed target profit, the acceptable maximum annual LGD is $4.25 \%$.

Substitute $r=10.5285 \%, r_{C}=5.57 \%, r_{P}=0 \%$ in break-even conditions into (21), and we get the acceptable maximum annual LGD $r_{D}$ of loan in break-even conditions: $r_{D 2}=r-r_{C}-r_{P}=10.5285 \%-5.57 \%-0 \%=4.96 \%$. It means 
TABLE 4: The decision assessment results for farmers' microfinance.

\begin{tabular}{lccccc}
\hline (1) Credit rating & (2) Annual LGD & (3) Contrast 1 & (4) Loan or not for contrast 1 & (5) Contrast 2 & (6) Loan or not for contrast 2 \\
\hline AAA & $0.114 \%$ & $0.114 \%<4.25 \%$ & & $0.114 \%<4.96 \%$ & \\
AA & $0.959 \%$ & $0.959 \%<4.25 \%$ & Agree to lend & $0.959 \%<4.96 \%$ & Agree to lend \\
A & $1.598 \%$ & $1.598 \%<4.25 \%$ & & $1.598 \%<4.96 \%$ & \\
BBB & $2.875 \%$ & $2.875 \%<4.25 \%$ & & $2.875 \%<4.96 \%$ & \\
\hline BB & $4.276 \%$ & $4.276 \%>4.25 \%$ & \multirow{2}{*}{ Reject lending } & $4.276 \%<4.96 \%$ & Agree to lend \\
B & $4.919 \%$ & $4.919 \%>4.25 \%$ & & $4.919 \%<4.96 \%$ & \\
\hline CCC & $6.641 \%$ & $6.641 \%>4.25 \%$ & & & \\
CC & $10.981 \%$ & $10.981 \%>4.25 \%$ & Reject lending & $10.981 \%>4.96 \%$ & Reject lending \\
C & $14.797 \%$ & $14.797 \%>4.25 \%$ & & $14.797 \%>4.96 \%$ & \\
\hline
\end{tabular}

that, on the premise of break-even, the acceptable maximum annual LGD is $4.96 \%$.

(3) Make the Credit Decision of Farmers' Microfinance. (a) The annual LGD of farmers in Ratings AAA, AA, A, and BBB are $0.114 \%, 0.959 \%, 1.598 \%$, and $2.875 \%$, respectively, which are lower than the acceptable maximum annual LGD $4.25 \%$ on the premise of guaranteed target profit, as shown in the third column of Table 4 . Therefore, the target profit of the bank can be ensured when the bank issues loans to the farmers in those four credit ratings.

(b) The annual LGD of farmers in Ratings BB and B are $4.276 \%$ and $4.919 \%$, respectively, which are higher than the acceptable maximum annual LGD $4.25 \%$ on the premise of guaranteed target profit whereas they are lower than the acceptable maximum annual loss given default $4.96 \%$ on the premise of break-even, as shown in the fifth column of Table 4. Therefore, the break-even of the bank, rather than the target profit, can be ensured when the bank issues loans to the farmers in Credit Ratings BB and B.

(c) The annual LGD of farmers in Ratings CCC, CC, and $\mathrm{C}$ are $6.641 \%, 10.981 \%$, and $14.797 \%$, respectively, which are higher than the acceptable maximum annual loss given default $4.96 \%$ on the premise of break-even. Therefore, the bank is likely to suffer a loss when it issues loans to the farmers in Credit Ratings CCC, CC, and C.

\section{Conclusions}

Decision assessment theory is one of the hot topics in the literature. Lots of decision-making optimization and evaluation methods have been proposed in the existing studies. Nonetheless, only a small part of them have been widely used in reality, especially in credit risk evaluation of commercial banks. In order to help the bankers or credit clerks to locate the good customers which can realize the bank's target profit, we conduct the credit risk decision evaluation of commercial banks. First of all, this paper creates an optimal credit rating model which consisted of an objective function and two constraint conditions. In the model, the first constraint condition of the strictly increasing LGDs eliminates the unreasonable phenomenon that the higher the credit rating is, the higher the LGD is. Secondly, the paper proposes a credit decision-making assessment method on the basis of measuring the acceptable maximum LGD of commercial banks. Finally, the proposed model is verified by the data from 2817 farmers' microfinance of a large-scale Chinese commercial bank. Empirical analysis results are provided below. (1) The proposed approach can accurately find out the good customers from all of the customers who applied for loans. (2) The target profit of bank can be ensured when the bank issues loans to the farmers in Ratings AAA, AA, A, and BBB. (3) The bank is likely to suffer a loss when it issues loans to the farmers in Ratings CCC, CC, and C.

The contributions of the paper lie in three aspects. First, the decision assessment of the credit risk of commercial banks from the loss given default (LGD) of customers, the breakeven point of customers' loan, and the target profit of commercial bank perspective, instead of a more traditional credit risk perspective, seems to offer a new insight into the credit rating of customers. Second, this paper proposes a novel decision assessment method which is suitable for customers' credit risk evaluation and credit decision. Third, our research not only has practical significance for decision assessment of the 2817 farmers' microfinance, but also provides a reference for credit risk evaluation and lending decision of customers in other commercial banks in the world.

This paper has some interesting extensions. Farmers' loan pricing can be included in the future extended model based on the proposed decision assessment approach. Moreover, the empirical results are derived from the 2817 farmers' microfinance data, which may not be generalized enough for all loan farmers in China. When investigating sustainability issues, there are also concerns about more relevant data. In addition, generalizing this decision assessment approach to other types of loan customers is not too difficult and researchers can easily conduct credit risk evaluation and credit decision through cases and empirical studies.

\section{Competing Interests}

The authors declare that there is no conflict of interests regarding the publication of the paper.

\section{Acknowledgments}

The research was supported by the National Natural Science Foundation of China (nos. 71503199, 71471027, 71373207, 
71301017, and 71273037), the Project Funded by China Postdoctoral Science Foundation (nos. 2015M572608 and 2016T90957), the Shaanxi Province Postdoctoral Science Foundation Funded Project, the Basic Business Project of Humanities Social Sciences for Central University (no. 2015RWYB09), the Natural Science Basic Research Project in Shaanxi Province (no. 2016JQ7005), and the China Ministry of Education Social Sciences and Humanities Research Youth Fund Project (no. 16YJC630102). The authors thank the organizations mentioned above.

\section{References}

[1] T. R. Hawkins, B. Singh, G. Majeau-Bettez, and A. H. Strømman, "Comparative environmental life cycle assessment of conventional and electric vehicles," Journal of Industrial Ecology, vol. 17, no. 1, pp. 53-64, 2013.

[2] A. Chen, H. Yang, H. K. Lo, and W. H. Tang, "Capacity reliability of a road network: an assessment methodology and numerical results," Transportation Research Part B: Methodological, vol. 36, no. 3, pp. 225-252, 2002.

[3] B. Shi, H. Yang, J. Wang, and J. Zhao, "City green economy evaluation: empirical evidence from 15 sub-provincial cities in China," Sustainability, vol. 8, no. 6, article 551, 2016.

[4] T. Aven, "Risk assessment and risk management: review of recent advances on their foundation," European Journal of Operational Research, vol. 253, no. 1, pp. 1-13, 2016.

[5] B. F. Shi, J. Wang, J. Y. Qi, and Y. Q. Cheng, "A novel imbalanced data classification approach based on logistic regression and Fisher discriminant," Mathematical Problems in Engineering, vol. 2015, Article ID 945359, 12 pages, 2015.

[6] E. I. Altman, "Financial ratios, discriminant analysis and the prediction of corporate bankruptcy," The Journal of Finance, vol. 23, no. 4, pp. 589-609, 1968.

[7] E. I. Altman, R. G. Haldeman, and P. Narayanan, "ZETATM analysis: a new model to identify bankruptcy risk of corporations," Journal of Banking and Finance, vol. 1, no. 1, pp. 29-54, 1977.

[8] J. H. Min and Y.-C. Lee, "A practical approach to credit scoring," Expert Systems with Applications, vol. 35, no. 4, pp. 1762-1770, 2008.

[9] R.-C. Hwang, H. Chung, and C. K. Chu, "Predicting issuer credit ratings using a semiparametric method," Journal of Empirical Finance, vol. 17, no. 1, pp. 120-137, 2010.

[10] G. M. Gupton, C. C. Finger, and M. Bhatia, Creditmetrics: Technical Document, J. P. Morgan \& Co. Incorporated, New York, NY, USA, 1997.

[11] K. Bijak and L. C. Thomas, "Modelling LGD for unsecured retail loans using Bayesian methods," Journal of the Operational Research Society, vol. 66, no. 2, pp. 342-352, 2015.

[12] B. Twala, "Multiple classifier application to credit risk assessment," Expert Systems with Applications, vol. 37, no. 4, pp. 33263336, 2010.

[13] S. Finlay, "Multiple classifier architectures and their application to credit risk assessment," European Journal of Operational Research, vol. 210, no. 2, pp. 368-378, 2011.

[14] J. Abellán and C. J. Mantas, "Improving experimental studies about ensembles of classifiers for bankruptcy prediction and credit scoring," Expert Systems with Applications, vol. 41, no. 8, pp. 3825-3830, 2014.
[15] M. B. Gorzałczany and F. Rudziński, "A multi-objective genetic optimization for fast, fuzzy rule-based credit classification with balanced accuracy and interpretability," Applied Soft Computing, vol. 40, pp. 206-220, 2016.

[16] S. H. Han, S. X. Lu, and S. C. H. Leung, "Segmentation of telecom customers based on customer value by decision tree model," Expert Systems with Applications, vol. 39, no. 4, pp. 3964-3973, 2012.

[17] C. Ljungwall, X. Yi, and Y. T. Zou, "Central bank financial strength and the cost of sterilization in China," China Economic Review, vol. 25, no. 1, pp. 105-116, 2013.

[18] R. Florez-Lopez, "Modelling of insurers' rating determinants: an application of machine learning techniques and statistical models," European Journal of Operational Research, vol. 183, no. 3, pp. 1488-1512, 2007.

[19] A. Pascucci, M. Suárez-Taboada, and C. Vázquez, "Mathematical analysis and numerical methods for a PDE model of a stock loan pricing problem," Journal of Mathematical Analysis and Applications, vol. 403, no. 1, pp. 38-53, 2013.

[20] Y.-S. Chen and C.-H. Cheng, "Hybrid models based on rough set classifiers for setting credit rating decision rules in the global banking industry," Knowledge-Based Systems, vol. 39, no. 4, pp. 224-239, 2013.

[21] Y. H. Guo, W. J. Zhou, C. Y. Luo, C. R. Liu, and H. Xiong, "Instance-based credit risk assessment for investment decisions in P2P Lending," European Journal of Operational Research, vol. 249, no. 2, pp. 417-426, 2016.

[22] S. Jones, D. Johnstone, and R. Wilson, "An empirical evaluation of the performance of binary classifiers in the prediction of credit ratings changes," Journal of Banking \& Finance, vol. 56, no. 4, pp. 72-85, 2015.

[23] Basel Committee on Banking Supervision, Basel III: A Global Regulatory Framework for More Resilient Banks and Banking Systems, Bank for International Settlements, 2010.

[24] The Postal Savings Bank of China (PSBC), Credit Risks Evaluation and Decision System of Microcredit for Farmers for the Postal Savings Bank of China, 2nd edition, 2011.

[25] The China Banking Regulatory Commission (CBRC), "Rules for regulating the risk rating system of joint-stock commercial banks," http://www.cbrc.gov.cn/chinese/home/docDOC_ReadView/301.html.

[26] The China Banking Regulatory Commission (CBRC), "Rules for regulating the capital adequacy requirement of commercial banks," http://www.cbrc.gov.cn/chinese/home/docView/189 .html.

[27] R. M. Stein, “The relationship between default prediction and lending profits: integrating ROC analysis and loan pricing," Journal of Banking \& Finance, vol. 29, no. 5, pp. 1213-1236, 2005. 

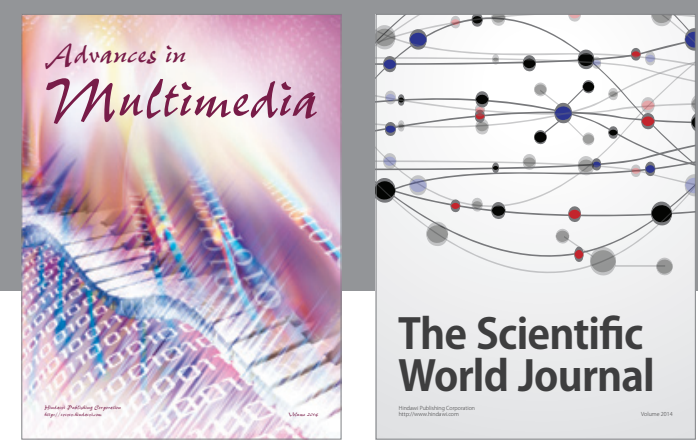

The Scientific World Journal
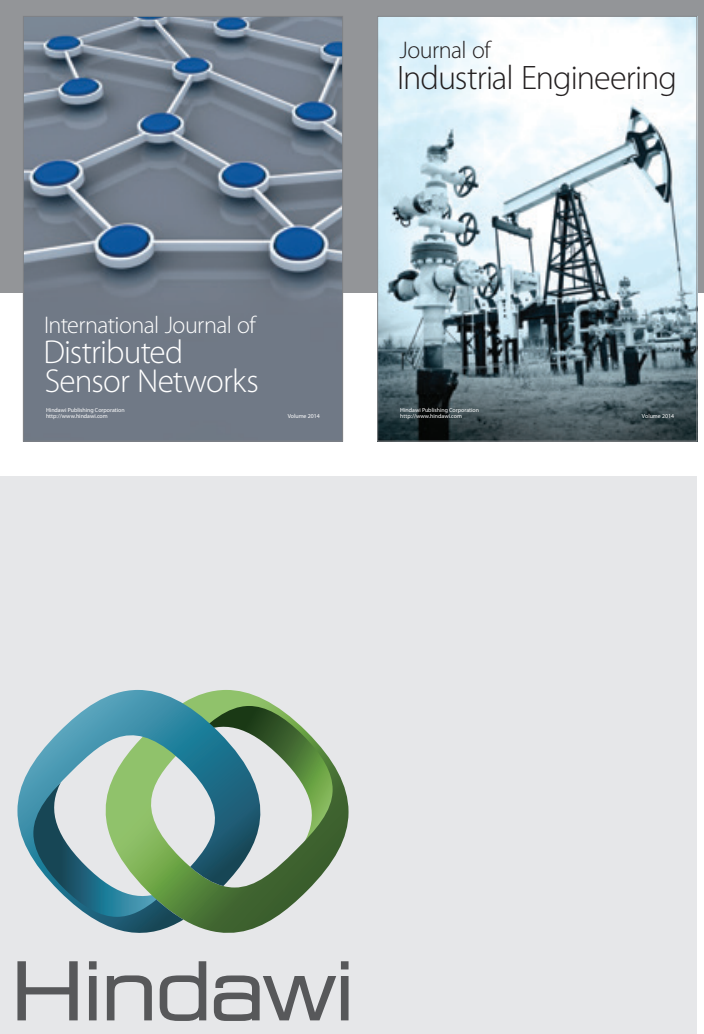

Submit your manuscripts at

http://www.hindawi.com

\section{Computer Networks} and Communications
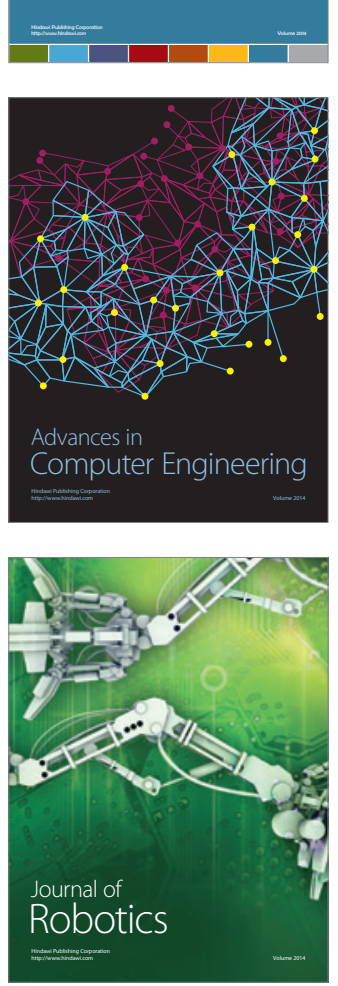
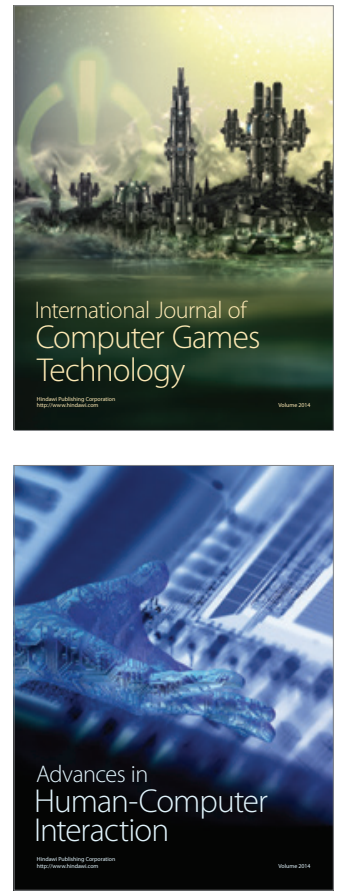
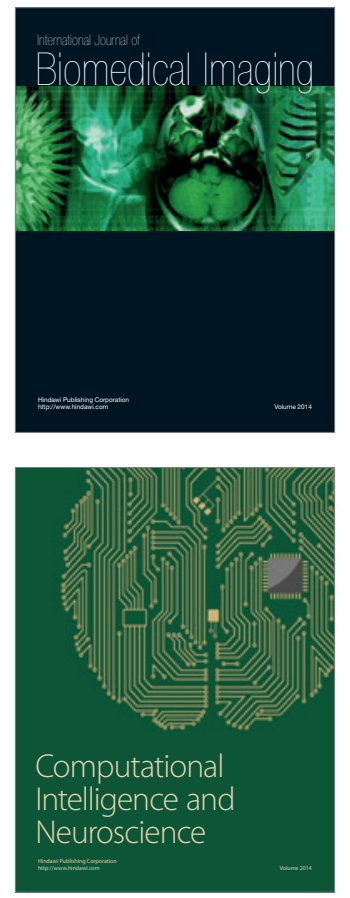
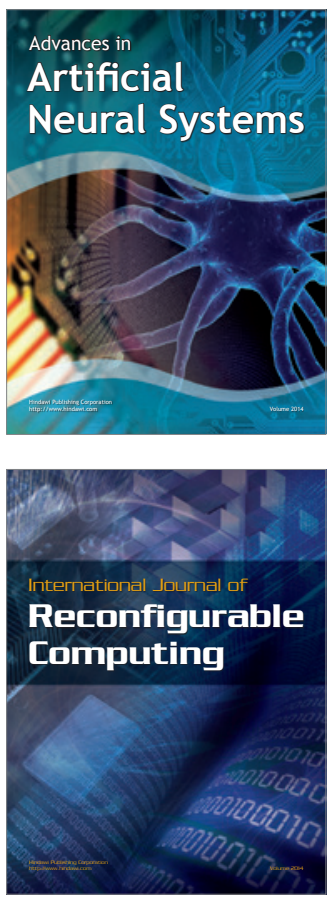
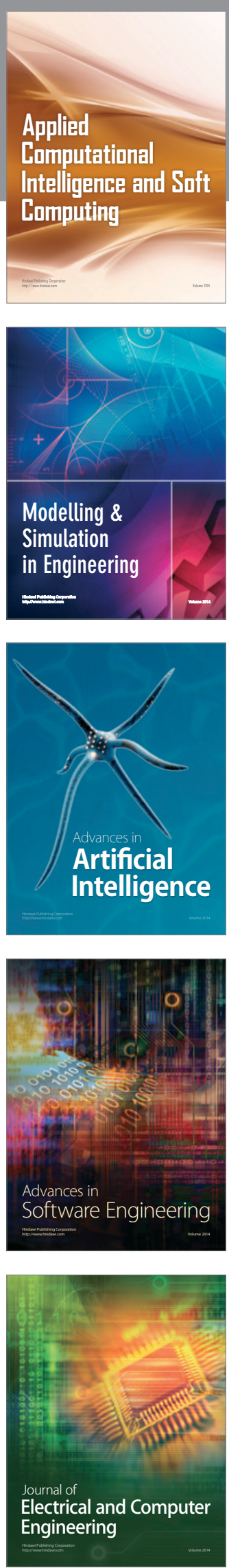